\title{
Esposos y amantes consanguíneos entre los tobas (qom) del Gran Chaco
}

Époux et amants consanguins chez les Toba (Qom) du Gran Chaco

Consanguine spouses and lovers among Toba (Qom) people of the Gran Chaco

Florencia Tola

\section{OpenEdition}

\section{Journals}

Edición electrónica

URL: https://journals.openedition.org/jsa/13742

DOI: $10.4000 /$ jsa. 13742

ISSN: $1957-7842$

Editor

Société des américanistes

Edición impresa

Fecha de publicación: 17 septiembre 2014

Paginación: 131-161

ISSN: 0037-9174

Referencia electrónica

Florencia Tola, «Esposos y amantes consanguíneos entre los tobas (qom) del Gran Chaco», Journal de la Société des américanistes [En línea], 100-1 | 2014, Publicado el 01 enero 2016, consultado el 03 septiembre 2022. URL: http://journals.openedition.org/jsa/13742 ; DOI: https://doi.org/10.4000/jsa. 13742

All rights reserved 


\title{
ESPOSOS Y AMANTES CONSANGUÍNEOS ENTRE LOS TOBAS (QOM) DEL GRAN CHACO
}

\author{
Florencia TOLA *
}

\begin{abstract}
A partir del material registrado entre los tobas (qom) del Gran Chaco, este trabajo expone aspectos centrales de su sistema de parentesco que expresan la existencia de un repliegue matrimonial endogámico. Hasta el momento, los tobas habían sido caracterizados por la etnografía de la región como un grupo chaqueño con una marcada propensión a la apertura, que se manifestaba matrimonialmente en la exogamia generalizada. Luego de describir el estado actual de los estudios regionales sobre parentesco, nuestro análisis de una extensa red matrimonial y de las relaciones clandestinas entre amantes echa luz sobre la manera en que, a lo largo de ocho generaciones, se produce la «elección » tanto del cónyuge como de los amantes. [Palabras clave: Gran Chaco, tobas (qom), parentesco, matrimonios consanguíneos, relaciones clandestinas.]
\end{abstract}

Époux et amants consanguins chez les Toba (Qom) du Gran Chaco. À partir de matériaux recueillis chez les Toba (Qom) du Gran Chaco, l'article expose les traits centraux de leur système de parenté et y révèle un phénomène de repli matrimonial endogame. Cela contraste avec les descriptions que l'ethnographie régionale faisait jusqu'à présent des Toba comme d'un groupe chaqueño caractérisé par une ouverture vers l'extérieur qui se réalisait, sur le plan matrimonial, par une exogamie généralisée. Après une présentation de l'état actuel des études de parenté dans le Chaco, l'analyse du réseau matrimonial et des relations clandestines entre amants met en lumière la façon dont les Toba " choisissent », tout au long de huit générations, tant leurs conjoints que leurs amants. [Mots-clés: Gran Chaco, Toba (Qom), parenté, mariages consanguins, relations clandestines.]

Consanguine spouses and lovers among Toba (Qom) people of the Gran Chaco. Based on material collected among the Toba (Qom) of the Gran Chaco, this article reveals central aspects of the Toba (Qom) kinship system that point to the existence of endogamous marriage patterns. Until now, ethnographic works on this region have characterized the Toba people as a group with a propensity to openness, supposedly expressed in the field

* Investigadora del Consejo Nacional de Investigaciones Científicas y Técnicas (CONICET) de Argentina, docente de la Universidad de Buenos Aires, Olazábal $15843^{\circ} \mathrm{C}, 1428 \mathrm{CABA}$, Buenos Aires, Argentina [tolatoba@yahoo.com.ar].

Journal de la Société des Américanistes, 2014, 100-1, pp. 131-161. C Société des Américanistes. 
of kinship by a generalized exogamy in marriage patterns. After describing the state of the field of regional studies about kinship, this article analyzes an extensive marriage network and the clandestine relationships within it to shed light on the ways in which the choice of spouses and lovers takes place over eight generations. [Key words: Gran Chaco, Toba (Qom), kinship, consanguine marriages, clandestine relationships.]

En este trabajo se analizarán algunos aspectos del sistema de parentesco de los tobas (qom) del Gran Chaco ${ }^{1}$ (ver Figura 1), específicamente, la tendencia nunca antes registrada a un repliegue matrimonial endogámico. Los qom han sido caracterizados por la etnografía de la región como un grupo con una marcada propensión a la apertura que se manifestaba matrimonialmente en la exogamia generalizada. Antiguamente, dicha exogamia tenía como referente, para algunos, la banda - considerada como una red de familias extensas - y, para otros, la tribu - concebida como un conjunto de bandas -, unidades sociales ambas que ya no tienen vigencia en la actualidad, siendo la «comunidad» el principal marco de referencia actual.

A lo largo de este artículo daré cuenta de la existencia de un repliegue matrimonial endogámico pasado y presente a partir del análisis de la red matrimonial toba y de las relaciones extraconyugales. Para ello, me remitiré al material de campo registrado en tres comunidades del Chaco central argentino (específicamente, del centro de la provincia de Formosa) ${ }^{2}$. En un primer momento, me concentraré en el modo en que tanto el debate endogamia/ exogamia como las relaciones extraoficiales fueron abordadas por la etnografía de la región, y describiré el estado actual de los estudios chaqueños sobre parentesco. En un segundo momento, me adentraré en el análisis de la red matrimonial y de las relaciones clandestinas - realizado a partir de los resultados obtenidos con el Programa informático para el tratamiento de datos genealógicos, $\mathrm{PUCK}^{3}$-, especialmente, en algunas características de los matrimonios consanguíneos y de las relaciones de proximidad ${ }^{4}$.

\section{Características generales del Parentesco ChaQueño}

Salvo contadas excepciones, el parentesco no suscitó la atención de los primeros etnólogos extranjeros, tampoco la de sus seguidores argentinos. En las monografías de Alfred Métraux, Erland Nordenskiöld y Rafael Karsten las referencias al parentesco son escasas. Entre los argentinos, el parentesco fue un tema de interés tan sólo de la etnografía de los años 1980, que no tuvo mayor eco en las generaciones sucesivas. En este artículo me detendré en las informaciones brindadas por algunos autores para mostrar el panorama - un tanto confuso que reina en los estudios sobre el tema. A mi entender, la ausencia de un consenso respecto de la exogamia o endogamia de banda y tribu deriva de la gran variedad 


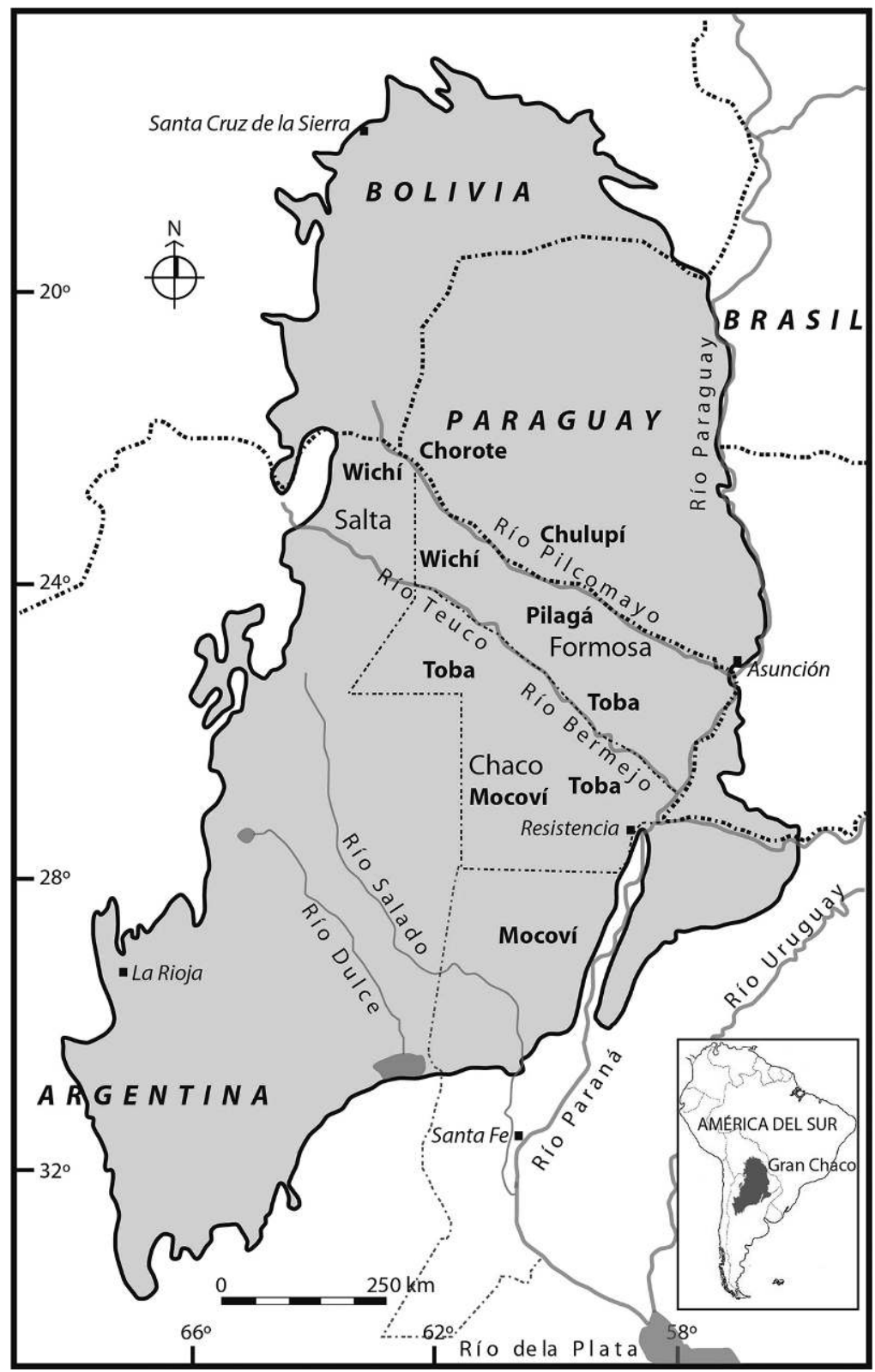

Fig. 1 - Mapa del Gran Chaco y de la distribución de los grupos mencionados en el texto [Celeste Medrano]. 
de términos utilizados para describir las unidades sociales (hordas, sub-tribus, tribus, bandas, comunidades, village communities, clanes, etc.), de la falta de explicitación de los límites de dichas unidades y de la ausencia de una perspectiva diacrónica que permita observar, a lo largo de varias generaciones y según los diversos momentos históricos, la alternancia entre matrimonios endogámicos (ya sean consanguíneos, entre miembros de una misma banda, tribu o grupo étnico) y exogámicos (contraídos fuera de la propia familia extensa, de la banda, tribu, comunidad o grupo étnico).

El sistema de parentesco toba es caracterizado en la bibliografía como un sistema con filiación cognática, con residencia post-marital uxorilocal y con una apertura hacia el exterior que se expresa en la exogamia de tribu - en su momento - o de familia extensa bilateral, y étnica hoy en día. Con respecto a la filiación (ver Figura 2), José Braunstein (1983a) sostenía que los grupos chaqueños seguían normas bilaterales a pesar de que algunos autores habían referido la existencia de una matrilinealidad. De hecho, para Karsten (1932), los tobas, los matacos, los chorotes y los chulupíes ${ }^{5}$ se regían por principios de linealidad femenina ${ }^{6}$. Métraux (1946), en cambio, aludía a una filiación patrilineal para los grupos chaqueños, ante lo cual John Palmer (2005) expresa que la filiación patrilineal entre los wichí actuales sólo prevalece en el contexto del liderazgo.

\begin{tabular}{l|l|l}
\multicolumn{1}{c}{ Bilateral } & \multicolumn{1}{c}{ Miliación } \\
\hline $\begin{array}{l}\text { Braunstein (1983a) para los } \\
\text { grupos chaqueños en general }\end{array}$ & $\begin{array}{l}\text { Karsten (1932) para los tobas, } \\
\text { matacos, chorotes y chulupíes }\end{array}$ & $\begin{array}{l}\text { Métraux (1946) para los gru- } \\
\text { pos chaqueños en general }\end{array}$ \\
\hline $\begin{array}{l}\text { Palmer (2005) y Barúa (2007) } \\
\text { para los wichi (matacos) }\end{array}$ & Siffredi(1973) para los chorotes & $\begin{array}{l}\text { Palmer (2005) para los wichí } \\
\text { (matacos) sólo en el contexto } \\
\text { del liderazgo }\end{array}$
\end{tabular}

FIG. 2 - Posiciones de chacólogos sobre la filiación.

Asimismo, existe en la bibliografía una serie de posiciones no concordantes en lo que respecta la endogamia o exogamia de banda o tribu (ver Figura 3). En 1932, Karsten escribía que, en la medida en que los habitantes de una village community eran parientes, los matrimonios no tenían lugar entre ellos ${ }^{7}$. Según él, los matrimonios se contraían entre personas que pertenecían a comunidades locales (poblados) diferentes, pero a una misma sub-tribe. Miller, después de describir las comunidades de los años 1960 como predominantemente exógamas (1966), indica que en el pasado las bandas solían ser endógamas (1979) ${ }^{8}$ y, sin mayores explicitaciones, expresa que la exogamia posterior sería una transformación de la endogamia antigua (1980). Métraux, por su parte, cuando se refiere a los « indios a pie » (foot Indians) del Gran Chaco, entre los cuales incluye a los tobas que conoció ${ }^{9}$, expresa que éstos podían casarse dentro de la misma banda (1946, p. 302). Por el contrario, Braunstein refiere a una regla de exogamia de 
banda ya que, entre los tobas y los pilagás, las bandas « constituían una familia entre cuyos miembros el matrimonio estaba expresamente descartado » (1983a, p. 82) ${ }^{10}$. En el caso de los tobas, esta exogamia de banda habría coexistido, según él, con una regla de endogamia tribal ${ }^{11}$, aun si las tribus guaycurúes (y, entre ellas, los tobas) eran, a pesar de esta regla, las más proclives a « los matrimonios inter-tribales e inclusive inter-étnicos » (ibid.).

Otros especialistas argentinos (Carrasco 1986, Mendoza 1999) apoyan la idea expresada por Braunstein de una exogamia de banda. Edgardo Cordeu y Miguel de los Ríos (1982), por el contrario, consideran esta unidad como endógama, apoyándose en Branislava Súsnik (1978) quien, a partir de los datos del padre Lozano, habla de la endogamia de banda de los grupos guaycurúes del siglo XVIII, considerados como posibles antecesores de los actuales tobas (Cordeu y De los Ríos 1982, pp. 163-164).

\begin{tabular}{l|l|l|l}
\multicolumn{1}{c|}{ Autor } & \multicolumn{1}{c|}{ Grupo indígena } & \multicolumn{1}{c}{ Endogamia } & \multicolumn{1}{c}{ Exogamia } \\
\hline Karsten (1932) & toba & de sub-tribu & de comunidad local \\
\hline Miller (1966) & toba & n. e. & de comunidad \\
\hline Miller (1979) & toba & de banda & n. e. \\
\hline Métraux (1946) & $\begin{array}{l}\text { indios a pie (incluidos } \\
\text { los toba-pilagás) }\end{array}$ & $\begin{array}{l}\text { posibilidad de casarse } \\
\text { dentro de la banda }\end{array}$ & n. e. \\
\hline Braunstein (1983a) & $\begin{array}{l}\text { pilagá } \\
\text { toba }\end{array}$ & $\begin{array}{l}\text { n.e. } \\
\text { de tribu (regla) }\end{array}$ & $\begin{array}{l}\text { de banda (regla) } \\
\text { de banda (regla) } \\
\text { de tribu, de etnia } \\
\text { (proclividad) }\end{array}$ \\
\hline Carrasco (1986) & toba y pilagá & n. e. & de banda \\
\hline Mendoza (1999) & toba-pilagá & n. e. & n. e. \\
\hline $\begin{array}{l}\text { Cordeu y De los Ríos } \\
\text { (1982) con base en }\end{array}$ & $\begin{array}{l}\text { guaycurú s. XviII y } \\
\text { toba s. Xx }\end{array}$ & de banda &
\end{tabular}

FIG. 3 - Posiciones de chacólogos sobre endogamia/exogamia toba. [n. e.: no especificado.]

Con respecto a la terminología de parentesco, Métraux (1937), Miller (1966), Vellard (1969) y Braunstein (1976) describieron la terminología toba de referencia. Ésta es una terminología cognática, idéntica para ego masculino y femenino, y con un marcado carácter clasificatorio. Los tobas cuentan con una amplia red de parientes a los que clasifican como « consanguíneos » (lamo, n’huol'ec, lamochiguiñot, lapachaxaua, lpinecpi) ${ }^{12}$ o, en castellano, « familia », por oposición al término "parientes » que los mismos tobas utilizan para designar a los afines

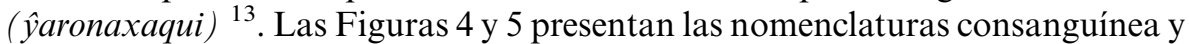
afinal respectivamente, tanto de referencia como vocativa. Como se observa, no establecen diferencia entre parientes cruzados y paralelos. Es una terminología hawaïana en $\mathrm{G} 0$ y esquimal en $\mathrm{G}+1$ y $\mathrm{G}-1$, tal como parecería ser la regla en los sistemas de parentesco chaqueños (para los matacos, véase Palmer 2005; para los pilagás, Dell'Arciprete 1991-1992; y para los tobas, Tola y Salamanca 2009). 


\begin{tabular}{|c|c|c|c|c|}
\hline Generación & $\begin{array}{c}\text { Término } \\
\text { de referencia }\end{array}$ & Término vocativo & $\begin{array}{c}\text { Parientes } \\
\text { directos }\end{array}$ & $\begin{array}{c}\text { Parientes } \\
\text { colaterales }\end{array}$ \\
\hline \multirow{2}{*}{$G+2$} & yape' & yape & $\mathrm{PF}^{14}$ & PPB, PPPSbS, etc. \\
\hline & icote & come & PM & PPZ, PPPSbD, etc. \\
\hline \multirow{4}{*}{$\mathrm{G}+1$} & ita'a & papá o taxare & $\mathrm{F}$ & \\
\hline & yate'e & mamá o chera & $\mathrm{M}$ & \\
\hline & ñitesoqo' & tío o tesoqolec & & PB, PPSbS, etc. \\
\hline & yasoro & tía o sorole' & & PZ, PPSbD, etc. \\
\hline \multirow{5}{*}{ G 0} & $\tilde{y} a q a$ & $\tilde{y} a q a$ & $\mathrm{Sb}$ & $\begin{array}{l}\text { PCh, PSbCh, PPSbChCh, } \\
\text { etc., PSpCh }\end{array}$ \\
\hline & ỹapichaqa' & pichoqolec & $\mathrm{eB}$ & \\
\hline & yapilte & pilo'ole & $\mathrm{eZ}$ & \\
\hline & yanoqlec & yanoqolec & yB & \\
\hline & no'ole & no'ole & $\mathrm{yZ}$ & \\
\hline \multirow{4}{*}{$\mathrm{G}-1$} & $\tilde{y}$ alec & yalcolec & $\mathrm{S}$ & \\
\hline & $\tilde{y}$ yale & yalole & $\mathrm{D}$ & \\
\hline & yasoshec & ỹasoshecolec & & SbS, PSbChS, etc. \\
\hline & yasoshe & ỹasoshole & & $\mathrm{SbD}, \mathrm{PSbChD}$, etc. \\
\hline G-2 & iual & $\begin{array}{l}\text { iualole (alter fem.) } \\
\text { iualolec (alter masc.) }\end{array}$ & $\mathrm{ChCh}$ & $\begin{array}{l}\text { SbChCh, PSbChChCh, } \\
\text { etc. }\end{array}$ \\
\hline
\end{tabular}

Fig. 4 - Terminología consanguínea toba.

\begin{tabular}{|c|c|c|c|}
\hline Generación & $\begin{array}{l}\text { Términos } \\
\text { de referencia }\end{array}$ & $\begin{array}{l}\text { Términos } \\
\text { vocativos }\end{array}$ & Posición \\
\hline \multirow[b]{2}{*}{$\mathrm{G}+2$ y G+1 } & yacho' & yacho', yape* o tío* & 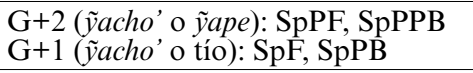 \\
\hline & yachoro & yachoro, come* o tía* & 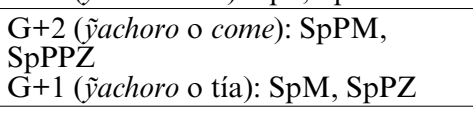 \\
\hline \multirow{5}{*}{ G 0} & iua & - & $\mathrm{W}, \mathrm{H}$ \\
\hline & yalle'e & yalle'e, $\tilde{y} a q a \tilde{y} a^{*}$ & $\mathrm{SbH}$, "Sb”H \\
\hline & ivete & ivete, yaqã̃a* & SbW, "Sb”W \\
\hline & idaua & 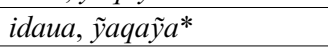 & SpSb, Sp"Sb" \\
\hline & yaronaxaua & naronagau' & 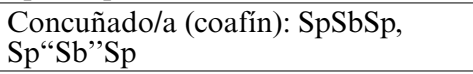 \\
\hline \multirow{2}{*}{$\mathrm{G}-1$ y $\mathrm{G}-2$} & yaronaxanec & $\begin{array}{l}\text { yalec*, yasoshec* } \mathrm{y} \\
\text { iualolec* }\end{array}$ & $\begin{array}{l}\text { G-1 (ỹalec, yasoshec): DH, DHB, } \\
\text { DH“"B"; SbDH, SbDHB, SbDH"B" } \\
\text { G-2 (iualolec): ChDH, ChDHB, } \\
\text { ChDH"B" }\end{array}$ \\
\hline & yate & $\tilde{y a l e}^{*}, \tilde{y}$ asoshe* y iualole* & $\begin{array}{l}\text { G-1 (ỹale, yasoshe): SW, SWZ, } \\
\text { SW“Z”; SbSW, SbSWZ, SbSW“Z” } \\
\text { G-2 (iualole): ChSW, ChSWZ, } \\
\text { ChSW“Z”” }\end{array}$ \\
\hline
\end{tabular}

Fig. 5 - Terminología afinal toba. [ ${ }^{*}$ Términos consanguíneos que acercan afectivamente a los afines. Las comillas ("Sb", "B", "Z") refieren a categorías clasificatorias.] 
Con respecto a las relaciones extraconyugales en el Gran Chaco, Braunstein identificó una institución wichí que « altera las normas de la organización social "reglamentada" o "ideal" » (1983b, p. 169). Comúnmente confundido con un matrimonio incipiente, el kyutislí era en realidad una forma " orgiástica » de relaciones entre los géneros que raramente conducía al matrimonio (De los Ríos 1978-1979, Braunstein 1983b). Cuando dichas uniones orgiásticas (que existían en la mayoría de los grupos chaqueños) producían embarazos, solían efectuarse abortos e infanticidios ${ }^{15}$. Esta institución rompía con las reglas de la residencia uxorilocal (la pareja se escapaba a otra comunidad) y con el valor de la fidelidad (no sólo involucraba a jóvenes solteros sino también a personas casadas). El estado de kyutislí era atribuido a la acción de una persona no-humana y, según Miguel de los Ríos (1978-1979), remitía al cortejo, a la seducción, al erotismo, a la inestabilidad, a la pasión y a la pérdida de control ${ }^{16}$. Idoyaga Molina atribuye al kyutislí, entre los pilagás, la causa del perjuicio del sistema tradicional del matrimonio $\left(1976\right.$, p. 65) ${ }^{17}$. Según la autora, la difusión del kyutislí habría causado inestabilidad en los matrimonios, el aumento del adulterio y la disolución de las parejas. Hasta las primeras décadas del siglo xx, el adulterio y el consecuente abandono de la esposa conducían a enfrentamientos abiertos entre las mujeres que peleaban con «plumeros de huesos y sus muñequeras de piel de ciervo munidas de pinchos " (ibid.). Si bien el kyutislí fue descrito por diversos etnógrafos entre los wichí, y si bien prácticas semejantes fueron referidas entre otros indígenas chaqueños, no encontramos estudios de parentesco entre los qom (ni entre otros grupos chaqueños) que vinculen los patrones de alianza matrimonial con la elección del amante.

\section{Reglas aNtiguas y ACTUALES DE PROHIBICIÓN DEL INCESTO}

En la bibliografía de la región hay un consenso sobre la existencia de prohibiciones matrimoniales más que de reglas positivas. El término toba deranaxa'n (3P.S. del verbo iran: « anunciar, dañar »), cuya traducción es " él/eso anuncia », se usa para referirse a una persona que cometió incesto o a un matrimonio incestuoso, aludiendo a su consecuencia negativa: una relación incestuosa, en palabras de un anciano, «anuncia que algún día va a desaparecer toda la familia ${ }^{18}$.

Métraux escribía que sobre los toba-pilagás no abundaba «información acerca del matrimonio preferencial ${ }^{19}\left(1946\right.$, p. $\left.324^{20}\right)$. En un texto anterior (1937) señalaba que no había podido desentrañar las prohibiciones matrimoniales a causa de las contradicciones en las que caía su informante. Sin embargo, en ese mismo texto escribía que creía « haber podido establecer como certera la unión frecuente de la sobrina con el hermano de la madre » (ibid., p. 384) así como el matrimonio con «la hija del hermano de la madre » (ibid.). 
Sin embargo, según él, estaba permitido también casarse con la prima cruzada patrilateral, mientras que sobre la prima paralela recaía la prohibición. Asimismo, señala que las relaciones incestuosas de un hombre con su madre o su hija eran condenadas con la expulsión de la tribu (1937), las de un hombre con su abuela eran motivo de burla, mientras que el matrimonio con una nieta imponía el pago de una compensación económica (información contradicha posteriormente).

Unos años antes, Karsten (1932) escribía que los tobas no se oponían al matrimonio entre primos. Sin embargo, en el mismo texto expresa sus dudas respecto de esta idea, al constatar que entre otros grupos chaqueños existía dicha prohibición. Contrariamente, Palavecino (1933) sostenía que la unión matrimonial entre « parientes » era prohibida por los pilagás, y que el matrimonio entre primos era considerado incestuoso. Ana dell'Arciprete sostiene que, entre los pilagás, la única « regla vigente es la de la prohibición de casarse con un pariente » (1991-1992, p. 19), término que incluiría a todos los parientes consanguíneos. Esta observación concuerda, en parte, con lo descrito por Karsten (« en parte » ya que él mismo duda de que el matrimonio entre primos esté permitido) y con lo referido parcialmente por Métraux, para quien tan sólo los primos paralelos serían interdictos. Dell'Arciprete menciona que el matrimonio de hijos de primos en 1.er grado no suele ser abundante. Lamentablemente, no ofrece información cuantitativa sobre este punto. A su vez, Carrasco expresa que no encontró entre los tobas y pilagás «interdicciones estrictas al matrimonio con gentes de otras comunidades, ni tampoco prescripciones matrimoniales expresas » (1986, p. 249). Las prohibiciones que refiere (con tías, primas y sobrinas) sólo se aplican dentro de la comunidad aunque, en su mismo seno, el matrimonio entre parientes en 2.o grado no sería interdicto (ibid., pp. 250-252). Esta sugerencia concuerda con lo expresado por Cordeu cuando escribe que « las reglas de exogamia se refieren exclusivamente a la interdicción matrimonial entre grados próximos de parentesco » (1969-1970, p. 81).

Todo esto nos conduce a un aspecto central del matrimonio entre los grupos chaqueños que refiere a la proximidad genealógica entre cognados. En la medida en que no encontramos para el Chaco corpus significativos de datos genealógicos, y que el análisis manual de las genealogías tiene sus limitaciones, es probable que los matrimonios entre parientes consanguíneos a partir del 2.o grado no siempre hayan sido reconocidos como tales. Quizás esto se haya constituido como una de las mayores limitaciones para la comprensión de las redes matrimoniales chaqueñas. Por estas limitaciones es posible que reglas matrimoniales no hayan sido percibidas, aunque los diversos autores hayan identificado « algunas formas matrimoniales "estratégicas" o en el mejor de los casos preferenciales » (Bossert et al. 2009, p. 51).

Las etnografías de Palmer (2005) y de Guadalupe Barúa (2007) sobre los wichí parecerían ser una excepción a la incertidumbre que reina en los estudios 
sobre la existencia de reglas matrimoniales positivas. Nos detendremos en sus conclusiones ya que existe también la idea generalizada de que el parentesco wichí difiere marcadamente del toba: la tendencia wichí al repliegue hacia el interior se opondría a la marcada apertura hacia los otros de los tobas. Tal como expresan Cordeu y De los Ríos (1982), mientras que los wichí tendrían sentimientos de « temor y desconfianza hacia todos los extraños» (ibid., p. 139), los tobas tendrían una aceptación ambigua de estos últimos; actitudes que se vincularían con las normas matrimoniales.

Tanto Palmer (2005) como Barúa (2007, p. 71) sostienen la existencia de una filiación cognática entre los wichí. Ésta « se combina con un sistema matrimonial basado en el intercambio directo » (Palmer 2005, p. 116). Si la modalidad más simple del intercambio directo es el intercambio de hermanas, él demuestra que lo que predomina entre los wichí es la afinidad serial, en la que un individuo contrae matrimonio dentro de una parentela con la que su propia parentela ya tejió lazos afinales (ibid., pp. 141-142). Estas alianzas no involucran exclusivamente a los siblings, sino que abarcan a numerosos otros cognados, incluso de generaciones diferentes. Esta afinidad serial (así sea que se presente bajo la forma de un intercambio en sentido clásico o de un redoblamiento por parientes del mismo sexo) es entendida por él como una variante del intercambio directo (ibid., pp. 141-142). Dentro de su corpus de 50 matrimonios, Palmer encuentra que el intercambio de hermanas reales y clasificatorias corresponde tan sólo a un $10 \%$ del total, aunque no brinda más detalles. Según sus datos, entre los wichí predominarían los matrimonios entre ego y tanto la hermana menor como la sobrina del cónyuge de un sibling suyo o de sus padres (ibid., p. 145). Él concluye que el "principio ordenador» que rige el sistema matrimonial wichí es « un sistema exógamo y preferencial que, al mismo tiempo, se vale de una categoría tácita de "esposa potencial" » (ibid., p. 141). Ésta corresponde, según él, a una « concuñada » (ibid., p. 144), es decir, una consanguinea de un afín de un consanguíneo (categoría que, para los wichí, incluye a los hermanastros). Por otro lado, Palmer señala que los wichí que contraen matrimonio dentro de la propia parentela son considerados antisociales. En su corpus, estas uniones consanguíneas corresponden a un $20 \%$ de los matrimonios ${ }^{21}$ aunque, tal como él expresa, « en la mayoría de los casos es posible trazar la relación de manera tal que la unión se define como exógama » (ibid., p. 151).

Barúa (2007), por su parte, se detiene en « las redes de alianza » y señala la existencia de una " amalgama de parientes [que] se conforma sobre todo a través del intercambio directo [sic] del matrimonio de un grupo de "hermanos" (o "primos" o "tíos" o "sobrinos" en cuanto, [en] su calidad de Mayor o Menor, ingresen en la categoría de sibling) con otro conjunto de "hermanas" " (ibid., p. 64). Luego de que la repetición de alianzas en una comunidad local agota las posibilidades de contraer tales matrimonios, se abre la posibilidad de incorporar ajenos (ibid.). Dentro de los «matrimonios preferenciales» (ibid., p. 68), la 
autora destaca el levirato y el sororato, el matrimonio entre cuñados luego de la separación del cónyuge, entre hermanastros («concuñados » para los wichí) $\mathrm{y}$, por último, entre un conjunto de hermanos y un conjunto de hermanas clasificatorios (siendo que los matrimonios entre bloques mixtos - es decir, intercambios propiamente dichos - no son mencionados por ella). Si para Palmer el sistema wichí es exógamo ya que, más que casarse entre consanguíneos, los wichí preferirían casarse en base a la afinidad serial, Barúa concluye que los redoblamientos corresponderían a una endogamia sociológica.

Si bien el corpus wichí y el toba registrado por mí poseen características que podrían ser influyentes en la contabilización de los matrimonios consanguíneos, si bien Palmer no da cuenta de los matrimonios con parientes consanguíneos clasificatorios y si bien existen diferencias entre el uso o no de un programa informático para el tratamiento de los datos genealógicos, por el momento el corpus wichí constituye el único disponible con el cual establecer comparaciones sobre los modos en que los indígenas chaqueños se casan. Por otro lado, mi objetivo es mostrar que los tobas no son necesariamente tan abiertos hacia el exterior a nivel matrimonial, por más de que un análisis más exhaustivo de un corpus wichí - incluso mayor que el existente - diera como resultado un porcentaje mayor que el actual de matrimonios entre consanguíneos. Basándonos en los datos que disponemos de los qom y los wichí, la diferencia entre ambos sistemas matrimoniales no sería a primera vista tan marcada. En efecto, tanto los matrimonios consanguíneos como aquellos que repiten alianzas no están ausentes entre los qom ni presentan un porcentaje tan bajo si tenemos en cuenta que la etnografía de la región los ha considerado muy abiertos y exógamos.

En la actualidad, los qom consideran incestuosas las relaciones amorosas (y por lo tanto los matrimonios) entre los miembros de una familia extensa bilateral. Un individuo no puede casarse con ningún sibling (real o clasificatorio) suyo (a quien denomina ỹaqaỹa), ni con quien clasifica como sibling (real o clasificatorio) de algún pariente suyo, de cualquier nivel genealógico, mientras exista memoria de la cadena genealógica que los une o mientras exista memoria de la relación clasificatoria de sus antepasados. En este caso, el uso de la terminología de parentesco operaría como un factor central en la regla de prohibición del incesto ${ }^{22}$. En cuanto a los afines, los únicos explícitamente prohibidos serían el cónyuge de un progenitor (fallecido o no) y de un hijo o de una hija (fallecido/a o no). Hoy en día, una relación con el cónyuge de un sibling es también considerada incestuosa mientras este último esté casado ${ }^{23}$. Esta prohibición es una de las menos respetadas. Hay casos en los que un cónyuge abandona a su pareja para juntarse con el sibling de ésta, pero es principalmente en el ámbito de las relaciones clandestinas en el que estas uniones se producen. Ahora bien, con la ayuda de PUCK mostraré primero que existen matrimonios entre cognados a lo largo de varias de las generaciones registradas, matrimonios 
que luego serán examinados a la luz de los criterios mnemónicos y terminológicos de los mismos tobas.

\section{CARACTERÍSTICAS Generales DEL CORPUS Y MATRIMONIOS CONSANGUíneOS}

Desde el 2000 he constituido un corpus a partir del relevamiento de las genealogías y de las historias de familias y parejas de tres comunidades del centro de la provincia de Formosa (San Carlos, Santo Domingo y Riacho de Oro) y de quienes han migrado al barrio peri-urbano de la capital provincial (Namqom o Lote 68$)^{24}$. Registré 1266 individuos (vivos y muertos); cifra que incluye a los habitantes pasados y presentes de las tres comunidades, a los que migraron a Lote 68 , así como a los parientes consanguíneos y afines de dichos habitantes que residen actualmente en otras comunidades.

El corpus registra individuos a lo largo de ocho generaciones, nacidos desde finales del siglo XIX hasta principios del XXI. Al respecto, Barry y Gasperoni (2008), en su trabajo sobre la amnesia y la información genealógica en dos corpus diferentes (uno etnográfico y otro histórico), llaman la atención sobre el hiatus existente entre la memoria que los actores poseen de su red de parentesco y la cantidad de generaciones comprendidas en un corpus. De hecho, si bien mi corpus registra unas cuantas líneas directas de 8 generaciones (116 líneas que bajan de 4 parejas apicales a 55 descendientes de $\mathrm{G}-7^{25}$ ), sólo un puñado de personas conoce integralmente tales líneas.

El corpus contiene 691 hombres y 575 mujeres, y registra 420 matrimonios entre 363 hombres y 345 mujeres. No evidencia matrimonios polígamos, pero sí contiene matrimonios consecutivos. De las 420 relaciones matrimoniales, $85(20,24 \%)$ son entre cognados que tienen entre sí una distancia máxima de 5 generaciones (i. e. que son como mucho primos en 4.o grado). Estos 85 matrimonios involucran a 151 individuos ( 73 hombres y 78 mujeres) y participan de 149 circuitos (o cadenas de parentesco cerradas por un matrimonio) repartidos en 101 tipos de circuitos ${ }^{26}$ (definidos éstos por la composición exacta de la cadena genealógica que vincula a un ego masculino [ô] con su esposa; por ej., ¿FFZSD sería un tipo, del que puede haber varias ocurrencias, cada una de las cuales correspondería a un circuito concreto).

Lo primero que salta a la vista es entonces que, al distribuirse los 149 circuitos entre 101 tipos, el promedio de circuitos empíricos en cada tipo es muy bajo. Pero, al agrupar estos tipos en « paquetes » de tipos teniendo en cuenta la terminología de parentesco, percibimos que la ocurrencia dentro de los conjuntos centrales no es tan reducida (Figura 6): 


\begin{tabular}{|c|c|c|c|c|c|c|}
\hline Gen. & $\begin{array}{c}\text { Categoría } \\
\text { terminológica }\end{array}$ & Circuitos & $\%$ & Matrimonios & Intersecciones & $\mid \begin{array}{c}\text { Matrim. sin } \\
\text { intersecciones }\end{array}$ \\
\hline G+2 & icote, « abuelas » & 6 & $4 \%$ & 6 & 1 « hermana » & 5 \\
\hline G+1 & ýasoro, « tías » & 26 & $17 \%$ & 19 & $8 \ll$ hermanas » & 11 \\
\hline G 0 & $\hat{y} w a q a \hat{y} a$, «hermanas» & 83 & $56 \%$ & 49 & $\begin{array}{l}1 《 \text { abuela » } \\
8 \ll \text { tías » } \\
7 《 \text { sobrinas » }\end{array}$ & 33 \\
\hline G-1 & yasoshe, « sobrinas » & 29 & $20 \%$ & 23 & $\begin{array}{l}7 \ll \text { hermanas } » \\
1 \ll \text { nieta } »\end{array}$ & 15 \\
\hline G-2 & iual, « nietas » & 5 & $3 \%$ & 5 & 1 《sobrina » & 4 \\
\hline Total & & 149 & $100 \%$ & 85 & & \\
\hline
\end{tabular}

FIG. 6 - Circuitos matrimoniales y matrimonios involucrados, agrupados en « paquetes » de tipos, de acuerdo a la terminología. Las últimas dos columnas indican el número de matrimonios con y sin lazos en otros « paquetes » respectivamente (por ej., primos con/sin otros lazos entre sí además de primos).

El mayor porcentaje de circuitos y matrimonios consanguíneos se da entre individuos considerados « hermanos » (primos reales y clasificatorios), a los que le siguen los circuitos y matrimonios con « sobrinas », « tías », « abuelas »y finalmente «nietas». Asimismo, en el cuadro se aprecia que en todos los «paquetes » terminológicos se encuentran matrimonios donde los cónyuges también tienen entre sí lazos que corresponden a otra categoría terminológica (por ejemplo, « hermanas » que, por otra vía, también son « sobrinas », « tías », etc.). Estos matrimonios se encuentran así en la intersección entre dos tipos de circuitos $^{27}$. Si observamos particularmente los 83 circuitos entre primos, encontramos que aquellos entre primos en 2.0 grado (34) constituyen el 41\%, mientras que el $43 \%$ está dado por los de primos en 3.er grado (36). Los porcentajes descienden para los primos más lejanos y más cercanos: $13 \%$ es el porcentaje de los de 4.0 grado (11) y 2,50\% el de los circuitos entre primos en 1.er grado (hay dos casos de primos paralelos y ninguno de primos cruzados). Ahora bien, la causa de que ni entre primos en 1.er grado ni entre aquellos en 4.o grado se produzca una cantidad significativa de uniones matrimoniales no es la misma para ambos casos. Probablemente el bajo porcentaje de los matrimonios entre primos en 4.o grado se deba a la ausencia de información genealógica que los podría vincular, mientras que el bajo porcentaje del matrimonio entre primos en 1.er grado se debe más bien a la prohibición matrimonial tan clara que recae sobre ellos.

Para retomar el debate sobre el repliegue wichí versus la apertura toba, si Palmer encuentra que alrededor del $20 \%$ de los matrimonios wichí se da entre consanguíneos (todos, como vimos, muy cercanos), yo registré que el $20 \%$ de los matrimonios tobas son entre consanguíneos clasificatorios. Este porcentaje 
muestra algunas particularidades del matrimonio toba. Primero, la prohibición explícita de casarse con cualquier consanguíneo bilateral no es respetada en la práctica. Ahora bien, varios ancianos mencionaron que la costumbre antigua consistía en no elegir al cónyuge fuera de la propia parentela. Acerca de las prácticas matrimoniales de la época en que los tobas poseían una alta movilidad, un anciano recuerda: « en esos tiempos no se juntan las tropas [tribus], cada tropa tiene su raza [es diferente a las otras y tiene un nombre particular], es prohibido casar una chica de otra tropa, entre tropa y tropa pelean. Cuando se empezaron a juntar con otras tropas [al sedentarizarse después de la conquista del Chaco], dejaron que se case con la de otra tropa ». La exogamia de tribu - o, ahora, de comunidad - no es en la actualidad formulada como norma. Nos enfrentamos entonces a dos contradicciones:

1. entre lo que varios ancianos refieren sobre el matrimonio recomendado antaño entre parientes y el repudio verbal que los adultos/jóvenes tienen ahora por dichos matrimonios,

2. entre los porcentajes no tan bajos de matrimonios consanguíneos y lo que se lee en la bibliografía sobre el incesto que representan las uniones consanguíneas (que coincide con lo que los tobas aseveran hoy en día).

Los datos del corpus permiten comprobar que los matrimonios consanguíneos que antiguamente eran recomendados se hallan distribuidos a lo largo de todas las generaciones documentadas. Incluso, a medida que descienden los grupos etarios, se ve ascender el porcentaje de personas casadas con un consanguíneo (Figura 7). Este aumento, como tal, es muy probablemente facticio y debido al incremento de la información genealógica disponible a medida que descienden los grupos etarios. Pero, al ser las franjas más jóvenes las más documentadas, sus porcentajes altos son los más acordes a la realidad.

La Figura 7 muestra además que, con el paso del tiempo, los individuos que se han ido casando con consanguíneos lo hicieron con parientes cada vez más lejanos. A medida que descienden los grupos etarios, los circuitos largos lógicamente aumentan en longitud y en cantidad por la razón ya indicada: la información genealógica se hace más completa y más profunda. Este aumento no es entonces significativo, y no se incluyó en el cuadro para no sobrecargarlo. En cambio, el hecho de que los circuitos más cortos - cuyos datos estarían disponibles en todas las generaciones - sólo aparezcan en las más ancianas sí es significativo. También lo es el aumento progresivo de las distancias mínimas que se observan entre los cónyuges (dejando de lado la franja 100-120, donde el único individuo con un matrimonio consanguíneo identificable - con una sobrina en 2.o grado - no permite inferir tendencias generales). 


\begin{tabular}{|c|c|c|c|c|c|}
\hline \multirow{2}{*}{ Grupo etario } & \multicolumn{3}{|c|}{ Individuos casados } & \multicolumn{2}{|c|}{ Circuitos más cortos } \\
\hline & total & con matrimonio consang. & $\%$ & Long. & n. ${ }^{\circ}$ parejas \\
\hline \multirow{2}{*}{$100-120$} & \multirow{2}{*}{124} & \multirow{2}{*}{1} & \multirow{2}{*}{$1 \%$} & 5 & 1 \\
\hline & & & & $\varnothing$ & $\varnothing$ \\
\hline \multirow{2}{*}{$60-100$} & \multirow{2}{*}{151} & \multirow{2}{*}{23} & \multirow{2}{*}{$15 \%$} & 3 & 1 \\
\hline & & & & 4 & 3 \\
\hline \multirow{2}{*}{$40-60$} & \multirow{2}{*}{187} & \multirow{2}{*}{50} & \multirow{2}{*}{$27 \%$} & 5 & 6 \\
\hline & & & & 6 & 15 \\
\hline \multirow{2}{*}{$20-40$} & \multirow{2}{*}{213} & \multirow{2}{*}{69} & \multirow{2}{*}{$32 \%$} & 5 & 4 \\
\hline & & & & 6 & 16 \\
\hline \multirow{2}{*}{$0-20$} & \multirow{2}{*}{20} & \multirow{2}{*}{8} & \multirow{2}{*}{$40 \%$} & 6 & 3 \\
\hline & & & & 7 & 1 \\
\hline Total & 708 & 151 & & & \\
\hline
\end{tabular}

FIG. 7 - Cantidad y porcentaje de personas con matrimonio consanguíneo en cada grupo etario, y distancias mínimas entre las parejas consanguíneas (se indicaron las dos longitudes más cortas que se dan en cada grupo). Los grupos etarios son estimativos y referidos al año 2000.

En síntesis, teniendo presente la terminología de parentesco, las reglas de prohibición del incesto y las cifras de las personas casadas con consanguíneos a lo largo de las generaciones, ni los wichí serían tan replegados ni los tobas tan abiertos. Ahora bien, a pesar de que las genealogías permitan obtener este porcentaje de uniones consanguíneas, ¿todas ellas son consideradas relaciones entre parientes? ¿Los qom conceptualizan a la totalidad de dichas relaciones como incestuosas? ¿Todos estos matrimonios tienen el mismo estatuto de proscripto? En este sentido, ¿los parientes cercanos y lejanos son considerados de igual manera en el momento de la elección matrimonial? Estas preguntas serán tratadas en el siguiente acápite a partir de casos concretos de matrimonios consanguíneos que se entrelazan con relinkings (redoblamientos).

\section{Matrimonios redoblados Y entrelazamiento CON MATrimonios CONSANGUÍNEOS}

Braunstein, Barúa y Palmer fueron quienes brindaron más información sobre los matrimonios redoblados entre los grupos chaqueños. En 1983, Braunstein expresaba que en algunos grupos chaqueños era común el intercambio de hermanas así como el sororato, el levirato y la poliginia sororal. En nuestro caso, si bien aún no contamos con resultados detallados sobre estos matrimonios, al censar mediante PUCK aquellos incluidos en un relinking con una distancia generacional máxima de 2 (es decir que en cada uno de los conjuntos intercasados 
se incluyen hasta primos en 1.er grado), aparecen 67 relaciones matrimoniales que involucran a 283 personas (143 hombres y 140 mujeres), en 332 circuitos de 131 tipos $^{28}$. Casi el $40 \%$ de los 420 matrimonios están así implicados en, por lo menos, un relinking (a veces en varios), lo que no impide que los cónyuges puedan ser también consanguíneos. Las cifras de ambas categorías no son entonces cumulativas (de los 85 matrimonios consanguíneos, sólo 14 no son parte de un relinking del grado buscado). Asimismo, cabe aclarar que una pareja puede estar contabilizada más de una vez dentro de los relinkings dado que puede participar de varios tipos de circuitos (por ejemplo, para 305 de la Figura 8, 339 es al mismo tiempo FBDD, FFZDSD, FMBDSD, MFMMBSSDD, MFMMBDDSD, MHZD, FBWDD, FBDHD y FBDHBD y, por ende, han sido contabilizados en cada uno de estos tipos). Los relinkings encontrados mediante PUCK se hallan sintetizados en la Figura 8:

\section{Relinkings}

\begin{tabular}{l|l|c}
\hline \multicolumn{1}{c}{ Bloque 1 } & \multicolumn{1}{c|}{ Bloque 2 } & Circuitos \\
\hline \multirow{4}{*}{ a. siblings reales y primos en 1.er gr. } & siblings reales y primos en 1.er gr. & 96 \\
\cline { 2 - 3 } & tío/a y sobrino/a reales & 99 \\
\cline { 2 - 3 } & padre/madre e hijo/a & 25 \\
\cline { 2 - 3 } & abuelo/a y nieto/a reales & 3 \\
\hline \multirow{3}{*}{ b. tío/a y sobrino/a reales } & tío/a y sobrino/a reales & 42 \\
\cline { 2 - 3 } & abuelo/a y nieto/a reales & 19 \\
\cline { 2 - 3 } & padre/madre e hijo/a & 6 \\
\hline \multirow{2}{*}{$\begin{array}{l}\text { c. abuelo/a y nieto/a reales } \\
\text { d. padre/madre e hijo/a }\end{array}$} & abuelo/a y nieto/a reales & 2 \\
\cline { 2 - 3 } $\begin{array}{l}\text { e. siblings reales y primos en 1.er gr., } \\
\text { padre/madre e hijo/a, tío/a y sobrino/a }\end{array}$ & madre/madre e hijo/a & 19 \\
\hline Total & madre/madre e hijo/a & 332
\end{tabular}

FIG. 8 - Relinkings entre dos bloques (o conjuntos) consanguíneos con distancia generacional máxima de 2 en cada bloque.

Los matrimonios consanguíneos siempre forman parte de un relinking y a veces son consecuencia de un relinking de generaciones anteriores ( $c f$. Hamberger y Daillant 2008). Veamos a continuación tan sólo algunos ejemplos significativos que mostrarán el entrelazamiento entre los matrimonios consanguíneos y redoblados.

El matrimonio entre 339 y 305 de la Figura 9 tiene, por un lado, en dos generaciones hacia arriba un intercambio de tipo hermano/a con hermano/a (41 y 42; 45 y 46). El matrimonio de los padres de 305 ( 85 y 86) fue un matrimonio entre tío/sobrina en 3.er grado y el de los padres de la esposa (339) fue un 


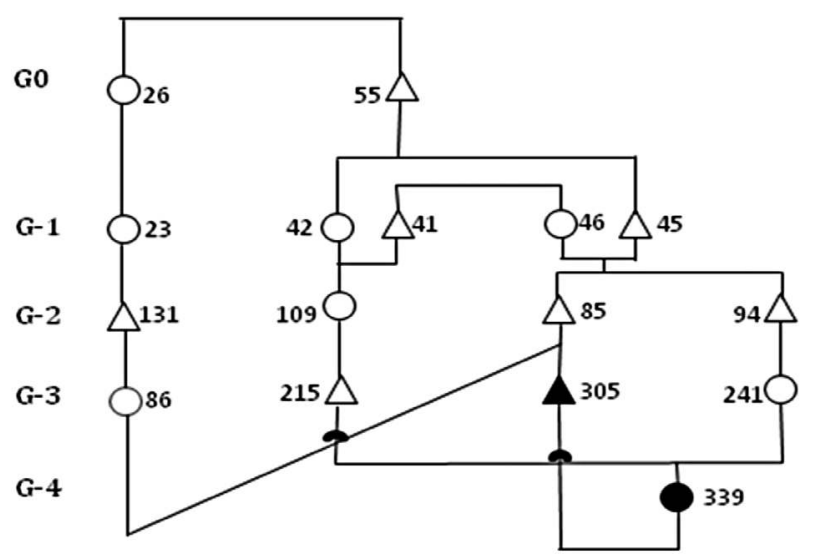

FIG. 9 - Matrimonios consanguíneos que anteceden al matrimonio entre 305 y 339.

matrimonio entre primos en 2.0 grado ( 241 y 215 ). Además de esto, los padres de ambos ya estaban relacionados genealógicamente: la madre de 339 (241) es la sobrina directa del padre del esposo y, por ende, la prima en 1.er grado del esposo. El matrimonio entre 339 y 305 es un matrimonio consanguíneo con intersección de circuitos (primos y tío/sobrina) a raíz de los dos matrimonios consanguíneos ocurridos entre las dos familias genealógicamente ya emparentadas (matrimonio oblicuo tío/sobrina clasificatorios - 85 y 86 - y matrimonio entre primos clasificatorios - 215 y 241 -). Por otra parte, 305 es tanto el primo en 1.er grado de la madre de su esposa, como el primo en 2.o grado del padre de su esposa. Es decir, que su esposa es su sobrina por dos circuitos en diversos grados: el de su prima en 1.er grado y el de su primo en 2.o.

Ahora bien, el matrimonio entre 339 y 305 no fue considerado incestuoso en la medida en que no es concebido como un matrimonio entre consanguíneos. ¿Por qué? Veamos en detalle. El matrimonio entre 215 y 241 fue considerado incestuoso en su época. Es un matrimonio entre primos en 2.o grado por diversos circuitos; primos que residían en la misma comunidad cuando se juntaron. La enfermedad que ella padecía cuando vivía fue atribuida al incesto. La hija de ellos, 339, se casó con 305 quien, como vimos, es su tío materno clasificatorio. Ahora bien, 305 no fue reconocido por su padre (85) y fue criado por su madre (86), quien se volvió a casar (con el sobrino directo de 85) y entregó a sus hijos a una de sus hermanas. Entonces, el matrimonio de 305 con 339 no fue considerado entre tío y sobrina, dado que el circuito que los relaciona de este modo es el que pasa por el padre de él, quien - a pesar de ser conocido como genitor - nunca fue considerado padre, ni lo crió como hijo. Además de tío y sobrina, 305 y 339 son 
también primos en 4.o grado. Este lazo, aunque pase por la madre de 305, tampoco es reconocido como tal, esta vez por la distancia que los separa de $26 \mathrm{y}$ 55 (sus tatarabuelos respectivos), de los cuales los jóvenes tienen un vago conocimiento y desconocen por completo las cadenas que descienden de ellos.

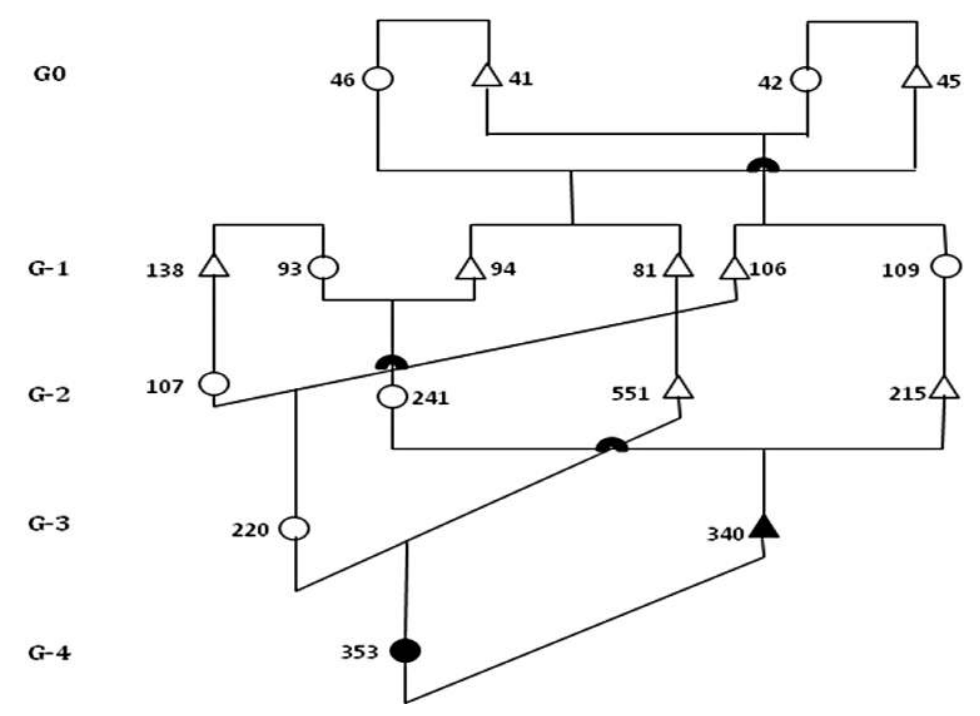

FIG. 10 - Matrimonios consanguíneos que anteceden al matrimonio entre 353 y 340.

El matrimonio entre 340 y 353 de la Figura 10 es un matrimonio entre primos en 2.o grado (MFBSD, FMBDD) y entre tío/sobrina (MMBDDD). Por una parte, los padres de la esposa forman parte de un relinking ya que el padre (551) se casó con 220, su FBWBDD, es decir la nieta clasificatoria (nieta del hermano) de la esposa de su tío paterno (94). Por el lado del joven (340), sus padres 215 y 241 no sólo eran primos en 2.o grado, sino más precisamente hijos de primos cruzados bilaterales dado que en la generación de sus abuelos hubo un intercambio de hermanas. Este intercambio antecede a tres matrimonios oblicuos en las generaciones descendientes. El matrimonio entre 340 y 353 tampoco es considerado consanguíneo debido, esta vez, a la distancia geográfica entre la madre de 353 (quien se fue de joven a Lote 68) y la familia del esposo que vivió en San Carlos. En este caso el recuerdo de quienes se hallan en los arcos de los circuitos que los relacionan como primos y como tío/sobrina parecería haberse diluido a raíz de la distancia geográfica y de la ausencia de vínculos estables entre sus descendientes. 


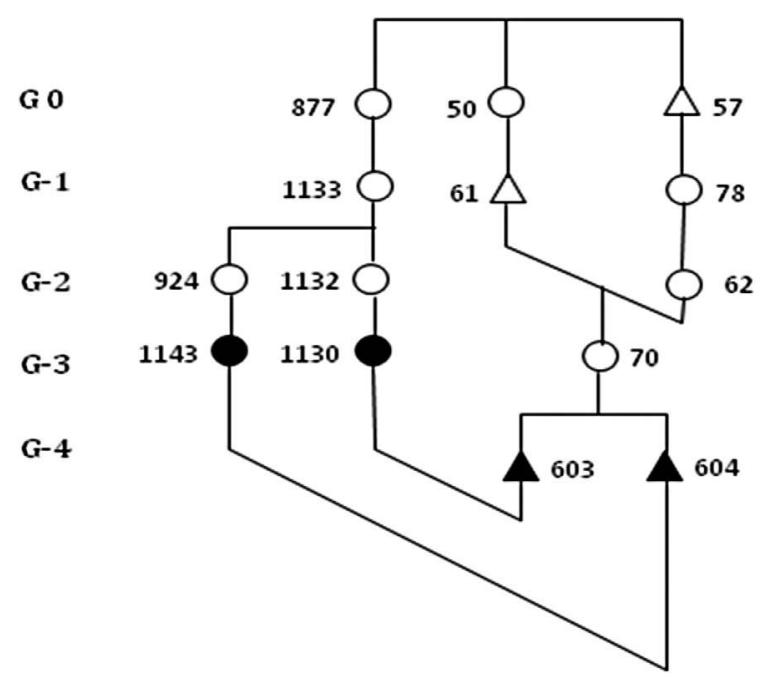

FIG. 11 - Matrimonios consanguíneos que anteceden al matrimonio entre 1143 y 604, 1130 y 603.

Los matrimonios entre las parejas de la Figura 11 tienen como antecedente un matrimonio tío/sobrina en 2.o grado entre los abuelos maternos de 603 y de 604 (61 y 62). Estos dos matrimonios, además de ser consanguíneos, constituyen un relinking en la medida en que 1143 se casó con el hermano del esposo de su prima en 1.er grado. Los matrimonios entre 1143 y 604, 1130 y 603 fueron y son abiertamente reprobados. De hecho, los hermanos 603 y 604 son nietos de 61 , de quien se recuerda que llamaba ỹaqaỹa (hermano/a) a 1133, la abuela de las dos primas-hermanas (esposas de 603 y 604). Resulta significativo que en esta reprobación de los matrimonios influye un hecho clasificatorio más que uno de orden genealógico. Es decir, los qom recuerdan el modo en que se llamaban entre sí los antepasados de los cónyuges y esto basta para condenar el vínculo de sus descendientes. Además de esta razón clasificatoria, la cercanía geográfica incide en la condena social, ya que los ascendentes tanto de las esposas como de los esposos vivían en la misma comunidad.

En síntesis, a lo largo de por lo menos cuatro generaciones encontramos matrimonios consanguíneos que se entrelazan con los redoblados. A partir de estos ejemplos cabe destacar que, si bien no nos encontramos ante una sociedad que posee una estructura elemental de parentesco, los matrimonios no se dan necesariamente de modo aleatorio ya que las uniones consanguíneas ocurren en un porcentaje no insignificante. El análisis diacrónico permite vislumbrar ciertas recurrencias a lo largo de las generaciones dando cuenta de que los matrimonios actuales qom no son un producto ahistórico, sino que intercambios 
matrimoniales pasados generaron los lazos que existen entre los actuales cónyuges. La preferencia por diversas formas de endogamia local (entre ellas, los matrimonios consanguíneos) concuerda además con un patrón de matrimonio en el que se unen personas de las mismas familias a lo largo de varias generaciones.

Ahora bien, ¿cuáles son las razones por las que algunos matrimonios son considerados como entre parientes consanguíneos y otros equivalentes en cuanto a las posiciones no lo son? Mientras la memoria de algún lazo es trasmitida, aunque no se recuerde la cadena exacta sino sólo la relación clasificatoria que une a dos cognados, éstos son evitados como pareja - al menos en las relaciones oficiales. Pero, en la medida en que muchos de los lazos que unen a una pareja se remontan hasta cuatro generaciones hacia arriba - momento de transición entre un parentesco que aún algunos reconocen y el olvido debido a un corte en la trasmisión de la información - varios de ellos no son considerados consanguíneos. En las historias familiares que vimos, el carácter no homogéneo de la memoria está ligado, en parte, a la distancia geográfica que, de hecho, promueve o posibilita el matrimonio consanguíneo aun si, según los tobas, dicha distancia no sería un factor que influya en el carácter prohibido de una relación consanguínea. Otro elemento que incide en el reconocimiento o no de cadenas genealógicas equivalentes se da cuando un hombre niega la paternidad a alguno de su progenie. Este hecho es suficiente para que el individuo no reconocido no sea considerado miembro de una familia a pesar de conocerse la paternidad «biológica » que, en estos casos, se descarta ya que no crea de por sí un lazo social.

\section{RELACIONES CLANDESTINAS DE PROXIMIDAD}

Si bien las relaciones matrimoniales con consanguíneos son reprobadas y suelen ser constantes las referencias a los peligros que producen, hemos visto que estas uniones eran y son frecuentes. Además de representar un gran número de las parejas constituidas, las relaciones entre cognados se producen también en la mayoría de los vínculos clandestinos registrados. Para su análisis, el programa informático permitió determinar la consanguinidad de los amantes y los circuitos por medio de los cuales están relacionados. Esta información se complementó con otra de orden cualitativo como son las historias de vida de algunas mujeres, las narraciones orales brindadas por los implicados en las relaciones clandestinas o por sus parientes cercanos y el seguimiento de las historias familiares desde el año 2002 hasta el presente. Asimismo, tal como sucede en otros ámbitos de la vida social - como la brujería -, baso mi interpretación en las acusaciones de infidelidad en tanto que, junto con las acusaciones de brujería, son las que generan las mayores tensiones en las comunidades ${ }^{29}$. Si bien las jóvenes mujeres suelen ser las que comienzan una relación amorosa, cuando hay una acusación de infidelidad, por más de que la idea generalizada es que la mujer " robó » al 
hombre casado, tanto hombres como mujeres son considerados igualmente propensos a la conquista amorosa ${ }^{30}$.

Lo que he registrado a lo largo de los años es que las parejas de jóvenes solteros y las relaciones entre amantes casados involucran a individuos consanguíneamente emparentados que poseen menor distancia genealógica que la que existe entre cónyuges consanguíneos. Gran parte de estas relaciones clandestinas son intercambios y redoblamientos de alianzas (inter e intrageneracionales). Las relaciones clandestinas y los casos de hijos no reconocidos dejan entrever un sistema paralelo de relaciones entre hombres y mujeres en el que existen recurrencias que, por más de que no hayan sido analizadas cuantitativamente, son concordantes con la información brindada por PUCK para las relaciones oficiales. Encontramos, por un lado, relaciones clandestinas consanguíneas (entre tíos/sobrinas clasificatorios y primos en diversos grados) y, por otro, relaciones consecutivas de una persona con dos siblings vivos, con dos primos en diversos grados y con un tío y su sobrino. Además, encontramos intercambios y redoblamientos.

Los casos presentados aquí no agotan la totalidad de los casos registrados (del mismo modo que los matrimonios entre parientes consanguíneos expuestos tampoco constituyen la totalidad). Sin embargo, fueron elegidos porque condensan una gran variedad de relaciones amorosas entre parientes consanguíneos. A continuación describo tres casos particulares para identificar los grados de consanguinidad e ilustrar que, a pesar de la no aceptación generalizada de estas relaciones, ellas son mantenidas sin alterar mucho la vida social de las parentelas (los nombres fueron modificados).

1. Olga es sobrina en 3.er grado de quien fue su amante, Pedro, por línea materna (éste llama ỹaqaỹa - « hermano/a » - a la madre de Olga, su prima en 2.o grado) a través de dos circuitos de relacionamiento. Cuando terminaron su relación clandestina, Pedro buscó otra amante en el pueblo más cercano. Según su esposa toba, cuando ella llegó a la casa de Pedro en el pueblo, le dijo a la mujer criolla que lavaba la ropa de su esposo que ella era la hermana de Pedro. La mujer criolla le trasmitió que ella era la esposa de Pedro. La esposa toba de Pedro se quejó ante él y, para manifestar su desaprobación, comenzó a ser amante de maestros criollos de la escuela. Al darse cuenta de que su esposo tenía otra esposa, ella expresó que comprendió el motivo por el cual éste no se encargaba de la subsistencia. Pedro habló con sus suegros y les pidió que interviniesen para que su esposa abandonara su actitud promiscua. Años más tarde, él continúa con la esposa criolla del pueblo y su esposa toba comenzó a ser amante del sobrino en 1.er grado de su esposo.

2. Ana convivía con su esposo Luis y con un joven, José. Según relatan en la zona, cuando el esposo viajaba a la provincia de Chaco, ella tenía como esposo al joven José. De hecho, todos aseveran que los dos últimos hijos de ella son de José 
por parecerse más a él que a Luis. Según relatan sus parientes, Luis no puede tener hijos y es por ello que los hijos que él cría son en realidad todos de otros padres. Uno de éstos es un primo en 1.er grado de Luis y otro es un tío en 1.er grado de este primo de Luis. Luego de unos años, la pareja decidió abandonar la comunidad y José también se mudó a otra.

3. Rubén y Graciela son pareja desde hace varios años. Ambos expresan sus dudas respecto de la fidelidad del otro. En una ocasión, Rubén decidió dejar a su esposa pero el padre de ella lo convenció de regresar. Graciela me expresó reiteradas veces que no le afectaría que él la dejara ya que él no la dejaba salir a trabajar con sus patrones criollos porque temía que ella se encontrara con otros jóvenes por el camino. Ella dejó de ir a trabajar y, al mismo tiempo, le prohibió a su esposo hablar con otras mujeres. Sin embargo, en una oportunidad lo encontró con su amante, Mariela, ante lo cual él le expresó que ella era su prima (relación que no es tal genealógicamente). Graciela comenzó las tratativas para dejar a su esposo por Miguel, un sobrino de ella en 2.o grado que es también su primo en 3.er grado. Los padres de éste habían aceptado la relación ya que conocían a la joven no sólo por el vínculo consanguíneo, sino porque ella es la hermana del esposo de una de sus hijas. Sin embargo, este joven nunca se casó con ella ya que prefirió hacerlo con la prima en 1.er grado de ella. En ese momento, Graciela comenzó otra relación de amante con un primo propio en 3.er grado. Al terminar esta relación, ella comenzó a tener un nuevo amante, Fabio, que era el hermano paterno de su esposo ya que se enteró de que su esposo era, a su vez, amante de la esposa de Fabio. Tanto Rubén como Graciela abandonaron las tareas de subsistencia del hogar. Actualmente, siguen juntos como esposos a pesar de que la relación de Graciela con el hermano del esposo generó la furia de su esposo quien la atacó con un cuchillo. Luego de que el suegro lo perdonara, Graciela aceptó continuar con él.

Estas relaciones entre amantes consecutivos muestran la preferencia por la cercanía parental para la creación de un vínculo amoroso. Específicamente, dentro de las relaciones clandestinas consanguíneas registramos relaciones entre un tío/a en 2.o y 3.er grado y su sobrina/o (caso 1,3) y entre primos clasificatorios (3.er grado: dos relaciones en el caso 3). Asimismo, encontramos casos de relinkings en los que una persona tiene por amante a dos primos/as en 1.er grado (caso 2, 3), a dos siblings (dos relaciones en caso 3) y a tío y sobrino reales (caso 1,2). Aparecen también casos de poliginia (caso 1) y de poliandria (caso 2) que involucran no sólo a personas de comunidades diversas, sino también a personas de la misma comunidad y hasta coresidentes. También ocupan un lugar importante los casos en los que existe un lazo entre el/la amante y el cónyuge (siblings, primos reales, tío/sobrino, cuñados, caso 1, 2, 3). Finalmente, se registraron casos en los que se aspira a lograr un intercambio: hermano y hermana con hermana y hermano (caso 3, intercambio no ocurrido). 
Si en los apartados precedentes mostré que la proximidad genealógica entre cónyuges contradice las normas explícitas actuales de prohibición del incesto, en éste intento dar cuenta de que las relaciones no conyugales ocurren entre parientes aún más próximos. Estas relaciones entre amantes expresan la continuidad de ciertas preferencias que, en el pasado, tal como se lee en Métraux y Karsten, no eran reprobadas pero que, en la actualidad, sí lo son. A pesar de esto, es notable que una misma distancia genealógica corta es más aceptada para amantes consanguíneos que para esposos. La tendencia a la endogamia actual de comunidad se expresa no sólo en las relaciones matrimoniales, sino también en aquellas no reconocidas oficialmente que, a lo largo del tiempo, tienen continuidad y se repiten de la misma manera. Cabe aclarar que los hombres qom suelen reconocer el beneficio de tener una amante en una comunidad relativamente distante ya que, gracias a los viajes para asistir a encuentros políticos o religiosos, ellos pueden visitarla y mantener una relación amorosa con una persona que no sea pariente. A pesar del beneficio de la distancia y del deseo generalizado explicitado de que la amante no sea pariente, los datos muestran que, al igual que las esposas, las amantes están geográfica y parentalmente cerca, y aún más.

El siguiente fragmento de la narración del chamán Juan brinda un panorama del modo en que las relaciones amorosas oficiales (expresadas por « juntarse ») se articulan con las clandestinas ( « estar » $\mathrm{o}$ 《 andar con »), generando un escenario en el que parientes consanguíneos se disputan tácitamente a sus compañeros sexuales y cónyuges:

En el Lote [Namqom] me encontré con una que fue mi novia. Hablamos y nos juntamos. Era buenita, no era celosa, pero una noche la encontré con otro. Mis suegros me engañaban, me decían que ella se quedaba en la casa. Nunca estaba la olla en el fuego. Al tiempo me fui a Bartolo [Bartolomé de las Casas] a curar a un señor [...] Él me pidió que me junté con su hija y me quedé pero después [...] me vine a San Carlos con ella que estaba embarazada. Era celosa. Cuando vuelvo del culto ya hay problemas, dice cualquier cosa [expresa sus celos]. En el culto se juntan las chicas y con un gesto te dicen de salir o con los ojos te sonríen, te aprietan la mano y ya te das cuenta de lo que quieren. Te dan una seña [...]. Con todas las chicas de San Carlos estuve. Primero con Susana. Llegaba a su casa, me quería juntar con ella. Pero una noche la encontré abrazada con mi hermano Luis. La dejé. Después me junté con Lucía y mi hermano con Susana [...] Lucía me quería hacer enojar, se acercaba a Luís adelante mío. Además me acusaron de que la mamá de Lucía se enferma siempre y dicen que es por mí. Dicen que a ella se le aparezco [en sueños] y se desmaya. [...] Mirta me habló para juntarse. Pero anoche me dijeron que anda con Luís y que Luís anda también con Ana, la esposa de Orlando, el que anda con Miriam.

Mediante PUCK se comprobó que Juan es primo en 2.o grado de Lucía a través de 2 circuitos (MMZDD, MFZSD), es primo en 2.o grado de Susana a través de dos circuitos (MMBDD, FMZDD) y que estas dos mujeres son primas 
en 2.o grado entre sí a través de un circuito (MFBDD). En el relato de Juan se puede advertir también la frecuente atracción de dos siblings por una misma persona. Si bien una relación con el cónyuge del sibling es considerada incestuosa, existen numerosos casos de siblings reales y clasificatorios que mantienen una relación amorosa con una misma persona sin ser considerados incestuoso ya que ninguno de los dos está casado con ella. La narración del chamán muestra asimismo la importancia de los celos en la unión conyugal y trasluce el rol de las obligaciones recíprocas entre hombres y mujeres dentro del matrimonio. Los celos de un cónyuge que duda de la fidelidad de su pareja hacen que él abandone sus responsabilidades económicas (caso 1, 3 y relato de Juan), lo que suele ser percibido por el/la amante como la más clara expresión de que el cónyuge está « entregando » a la persona deseada. El matrimonio es el espacio en el que ambos cónyuges tienen el derecho de reclamarle al otro las obligaciones que, de no ser cumplidas, estarían trasluciendo un deseo de quiebre de la unión conyugal. De hecho, hombres y mujeres rigen sus acciones en función no sólo de una filosofía social que enfatiza la autonomía individual, sino también la responsabilidad individual para con los afines y consanguíneos.

Terminar un matrimonio de muchos años es visto como un problema por dos motivos principales: el cónyuge dejado o su familia cercana puede emprender ataques brujeriles contra el que abandona, y un matrimonio es parte de una red matrimonial entre dos familias. Las acusaciones de infidelidad se vinculan entonces con aquellas de brujería cuando un matrimonio se disuelve por voluntad de uno de los cónyuges. Si dicho matrimonio es parte de una alianza entre dos conjuntos intercasados de consanguíneos, el conflicto en una de las parejas puede representar un fracaso de la alianza tejida a lo largo de varias generaciones. Por ello, cuando una persona abandona a su cónyuge, el consejo que trata de acatar es: "da analate’ aca arhua, nache maxat'chaxa come » (« cuando te separes de tu esposa, entonces ten cuidado después »).

En los casos de separación por infidelidad, si el amante no desea formalizar el vínculo, termina la relación, en cambio, si su intención es formalizarlo, él acepta la « entrega » (caso poco probable si los amantes son muy cercanos). La siguiente frase sintetiza esta idea: « Si Juan está vendiendo a Elena, yo la voy a comprar ». Esta « compra-venta » representa una transacción entre dos individuos o, mejor dicho, dos parentelas: entre el cónyuge traicionado y el amante. Es decir, prácticamente nunca las personas reconocen que alguien que abandona a su esposo/a lo haga movido por una decisión personal. La agencia está remitida a los dos términos entre los que se produce la sesión: el amante y el cónyuge abandonado. La metáfora de la compra-venta va de la mano de otra que expresa también las relaciones entre amantes, especialmente cuando es un hombre el que deja a su esposa por su amante: el robo. La expresión « adamaye ỹeguenaxan so lhua » (« ella robó al esposo ») remite a la fuga de dos amantes. Es decir, la compra-venta y el robo - términos que conllevan la idea del otro como una 
mercancía - son algunas de las maneras mediante las cuales los qom obtienen a sus parejas.

\section{REFLEXIONES FINALES}

La etnografía chaqueña resaltó siempre la inexistencia de reglas positivas de alianza matrimonial y la predominancia de proscripciones. Braunstein sostenía que « los modelos de organización social de los indios del Chaco [...] caerían en el grupo marginado en el trabajo de ese autor [Lévi-Strauss] que se caracteriza por poseer 'estructuras complejas' » (1983a, p. 98). Se entiende por complejo un sistema de alianzas matrimoniales en el que la elección del cónyuge depende de criterios que superan la órbita del parentesco. Por el contrario, en un sistema elemental la elección del cónyuge se orienta preferentemente, generación tras generación, hacia una categoría particular de parientes. En los sistemas complejos, la prohibición matrimonial suele recaer en un número reducido de parientes consanguíneos y afines, y « cada matrimonio representa una fórmula enteramente original, diferente de aquella de las uniones contraídas en las generaciones anteriores por los ascendentes directos y sus colaterales [...]» (Héritier 1981, p. 80). Fuera del espacio donde opera la prohibición del incesto, en las estructuras complejas la elección del cónyuge sería aleatoria y obedecería a las « leyes probabilísticas, hecho que implica que no se adapta a ninguna ley manifiesta de recurrencia o regularidad » (ibid.).

¿Corresponde entonces el sistema de parentesco toba de hoy en día a un sistema complejo si tenemos en cuenta que cada matrimonio no es « enteramente original » a pesar de la gran dispersión de tipos y que cada matrimonio no es independiente de aquellos ocurridos en generaciones precedentes? $\mathrm{O}$ ¿aun cuando la regla positiva no existe como tal ni explícitamente ni de manera institucional, es posible pensar que, tal como señala Héritier, el matrimonio consanguíneo toba expresa «una aprehensión individual de las zonas de familiaridad que se consideran favorables para la elección del cónyuge » (1981, p. 125)? ¿Existen relaciones amorosas consanguíneas que, por diversos motivos, sean las más buscadas o, al menos, estén más en el radio del pensamiento que otras?

En 2006, sin disponer de las herramientas informáticas para un análisis exhaustivo del corpus toba ni de la totalidad de éste, sugerí que el matrimonio qom se orientaba - al igual que el wichí - hacia los márgenes de las parentelas cognáticas (Tola 2006). La cuestión a indagar era cuáles eran dichos márgenes. PUCK permitió constatar que, más allá de las pocas uniones que se han producido entre consanguíneos cercanos (todos ya mayores de edad, cf. Figura 7), los matrimonios entre consanguíneos involucran a personas vinculadas en 2.o, 3.o y hasta 4.o grado, unidas entre sí a través de lazos múltiples. 
A lo largo de ocho generaciones registramos un promedio de $20 \%$ de matrimonios consanguíneos entre cognados cada vez más distantes. En la nomenclatura, los hijos de siblings reales y clasificatorios se denominan recíprocamente ỹaqaỹa y entre ellos el matrimonio está prohibido. Sin embargo, en la cotidianeidad, los yaqaỹa más distantes genealógica, social y geográficamente dejan de ser catalogados como parientes. Tanto la amnesia genealógica como la distancia geográfica hacen que no se los identifique explícitamente como tales y permiten que entre ellos se produzcan matrimonios. Si bien el constante uso de términos de parentesco permite que las nuevas generaciones se forjen un mapa de los vínculos que las unen con las generaciones anteriores - mapa que funciona, a la vez, como grilla de relacionamiento -, luego de dos o tres generaciones la información se diluye, dejando fuera del radio a los descendientes de primos en 2.o o 3.er grado.

A pesar de que el matrimonio entre consanguíneos distantes no corresponda a reglas positivas, esta modalidad - junto con los redoblamientos - permite en las comunidades pequeñas la perpetuación y la regeneración de las familias, el refuerzo de alianzas ya existentes entre parentelas emparentadas por alguna cadena que aparentemente se desconoce, y el evitamiento de que los parientes « se desparramen ", es decir, se alejen de sus comunidades y dejen de vivir rodeados de parientes.

Asimismo, en este trabajo intenté demostrar que el sistema de parentesco qom no puede ser analizado cabalmente si no se considera la forma en que se articulan el régimen de alianza matrimonial y el sistema paralelo de relaciones extraconyugales. Ya en 1983 Braunstein señalaba la existencia de una institución social wichí que debía ser estudiada y no confundida con el matrimonio (1983b). En nuestro caso, el análisis de las relaciones extramatrimoniales mostró que la elección de amantes y cónyuges se rige por principios semejantes, manifestando sin embargo algunas diferencias. Si bien muchos amantes y cónyuges son elegidos entre los parientes consanguíneos y redoblados (hecho que concuerda en parte con las observaciones de Métraux de los años en los que la sedentarización estaba aún en proceso), es en las relaciones entre amantes en donde registramos una distancia genealógica menor. Las relaciones premaritales y extramatrimoniales se dan entre parientes que antiguamente no eran vedados y que ahora lo son menos para amantes que para esposos. Los datos cuantitativos y aquellos de orden cualitativo presentados permiten repensar la supuesta preferencia qom por la apertura. Por el contrario, estaríamos presenciando una tendencia sociológica y genealógica al repliegue. *

* Manuscrit reçu en août 2012, accepté pour publication en juillet 2014. 


\section{Notas}

Agradezco principalmente a Isabelle Daillant por sus incansables indicaciones y enseñanzas, así como por el tiempo que tan generosamente me dedicó todos estos años. También agradezco al Centre EREA del LESC (CNRS) por acogerme en París en su laboratorio para trabajar con la Doctora Daillant; al grupo TIP (Traitement informatique de la parenté) y al Doctor Klaus Hamberger por la generosidad con la que estos años me brindó sus conocimientos sobre el programa informático PUCK.

1. El Gran Chaco constituye una llanura con porciones boscosas que comprende parte de Argentina, Bolivia, Paraguay y Brasil y que posee un área de más de un millón de $\mathrm{km}^{2}$. Esta región contiene un mosaico de ecosistemas, aunque predominan el bosque subtropical seco (en el oeste) y sub-húmedo (en el este) (Messineo et al., 2010). Los tobas pertenecen - junto con los pilagás y mocovíes - a la familia lingüística guaycurú y se autodenominan qom. Desde la época pre-colombina, todos ellos practicaban una economía nómade basada en la caza, la pesca y la recolección. Después de la conquista del Chaco argentino (comenzada en 1884), los tobas se asentaron en comunidades sedentarias y agrícolas rurales y, en las últimas décadas, se han movido a las afueras de las ciudades, constituyendo barrios y comunidades peri-urbanas.

2. Lo que analizo aquí son resultados de una investigación sobre el sistema de parentesco toba (PICT de la Agencia Nacional de Promoción Científica y Tecnológica 2007-2009 n. ${ }^{\circ} 32894$, PIP del Consejo Nacional de Investigaciones Científicas y Técnicas 2010-2012, n. ${ }^{\circ}$ 0059). Parte de lo abordado en este trabajo fue presentado en una conferencia en París (4 de junio 2010) en el Séminaire d'anthropologie américaniste, llevada a cabo en el Museo del quai Branly en el marco de una Beca externa para Jóvenes Investigadores (2010) del CONICET.

3. Program for the Use and Computation of Kinship data, creado en febrero 2007 por K. Hamberger, escrito en Java 1.6, Interface En, Fr, De, It, Es, publicado bajo la licencia CeCILL y disponible en www.kintip.net.

4. Entiendo por «matrimonios consanguíneos» aquellas relaciones matrimoniales que tienen lugar entre individuos con un ascendiente común conocido; y por « relaciones de proximidad» las relaciones conyugales y extraconyugales entre afines o consanguíneos cercanos genealógica y socialmente.

5. Si en las primeras etnografías de la región, los antropólogos se referían a un Chaco poblado por grupos chulupíes, moros, matacos, chamacocos y tobas, en la actualidad predomina referirse a ellos con los términos que estos grupos se dan a sí mismos: nivaklé, ayoreo, wichí, ishir y qom respectivamente. Sobre el tema de las denominaciones étnicas, $c f$. Combès (2006) y Richard (2011). A lo largo de este texto he optado por escribir en itálica y sin las marcas del plural del español aquellos gentilicios que no se han castellanizado (qom, wichi); mientras que se escribe sin itálica y con las marcas del plural del español los gentilicios que sí se castellanizaron (tobas, mocovíes).

6. Los chorotes tenían, según él, un verdadero « derecho materno » y una " ginecocracia », y otros grupos hasta un « relativo matriarcado» (Karsten 1932). La filiación materna de los chorotes es retomada unos años después por Siffredi (1973) quien expresa que los parientes maternos eran vedados para el matrimonio, mientras que no así los paternos. Braunstein (1983a) no acuerda con la postura de Karsten y sostiene que el finlandés confundía varios niveles, entre ellos, la localidad (los grupos chaqueños son en su mayoría matrilocales), el status jurídico-político de los sexos y las normas de filiación.

7. " [...] since the families belonging to the same village community are generally closely related to each other, marriages do not as a rule take place between persons of the same village " (Karsten 1932, p. 62).

8. "Toba communities tend to be exogamous, although no rule demands it » (1966, p. 194). Refiriéndose después a las bandas, expresa: «tendían a ser endógamas hasta décadas recientes [...] y un muestreo al azar sobre más de cincuenta parejas casadas de más de cuarenta años de edad mostró que el 80\% eran endógamas dentro de la misma banda » $(1979$, p. 27$)$. 
9. Los tobas se distinguen entre los del este (donde trabajo) y los del oeste (donde trabajó Métraux), estos últimos también conocidos como toba-pilagás por su proximidad lingüística, cultural y geográfica con los pilagás.

10. «La exogamia de banda está firmemente pautada en las tribus de habla Guaycurú » (Braunstein 1983a, p. 82).

11. En un texto posterior conjunto, Braunstein y Miller coinciden en esta antigua endogamia de tribu entre los tobas (1999, p. 10).

12. Lamochiguiñot y lamo poseen un significado que no surge del ámbito del parentesco. Lamo designa el «tronco de un árbol cortado que tiene las raíces bajo tierra ». Este término se usa en el parentesco para referirse a «los orígenes, la base, los antepasados, los abuelos ». Chigui-: raíz que parece indicar « proceder de », « venir de », -ñ-: sufijo direccional « hacia abajo », -ot: sufijo locativo « debajo de ». Los dos sufijos estarían siendo usados en sentido figurado para indicar la filiación. El término entero podría glosarse como « que viene hacia abajo/que desciende del tronco » (agradezco a Paola Cúneo por su ayuda con la glosa). Lapachaxaua y lpinecpi se vinculan porque ambos hacen uso del cuerpo para referirse a un consanguíneo. En el caso de lapachaxaua, lapat (aquí lapach-) carne, -ỹaxaua: sufijo que marca una relación. Lpinecpi, lpinec-: hueso, -pi: pluralizador. Un consanguíneo es, en función de estos dos términos, una relación a mi propia carne/hueso, un con-corporizado con el que existe un vínculo metonímico de cuerpo a cuerpo.

13. Ŷaronaxaqui es un lexema compuesto usado para referirse a «mi familia política » $\mathrm{o}$ «mis afines ». La raíz del verbo uaron (u-: 3P.S., -aron: raíz) es la que da lugar a varios términos de parentesco afinal. Yaronaxaqui está compuesto por el marcador de la 1P.S. $\tilde{y}$-, por la raíz del verbo casarse -aron-, por el sufijo nominalizador - $a x a$-y por el sufijo -qui que indica, entre otras posibilidades, " recipiente » (Messineo 2003, p. 105) o « lugar cerrado » (Buckwalter 2001, p. 370). Una traducción posible sería « mi familia circunscripta, obtenida por casamiento ».

14. P: parent (progenitor), F: father (padre), M: mother (madre), Sb: sibling (hermano/a), B: brother (hermano), Z: sister (hermana), Ch: child (progenie), S: son (hijo), D: daughter (hija), H: husband (esposo), W: wife (esposa), Sp: spouse (esposo/a), e: elder (mayor), y: younger (menor).

15. Sobre el tema, $c f$. Azara (1817 [1809], pp. 148-149), Ducci (1904, p. 5), Nordenskiöld (1912, p. 79), Karsten (1932, p. 53), Arnott (1935, p. 294 y p. 298) y Balmori (1957, p. 28).

16. Idoyaga Molina (1976) también estudió esta institución y refiere que entre los wichí el kyutislí designa el « enamoramiento » (quizás sea más preciso hablar de pulsión sexual). Estando en kyutislí, los jóvenes salían por los caminos en busca de pareja, se hacían pinturas faciales, usaban collares, adornos y ropas especiales, bailaban y tocaban música, $c f$. Karsten (1932, p. 53), Arnott (1935, p. 293), Métraux (1946, p. 324), Idoyaga Molina (1976, p. 52), De los Ríos (1978-1979, p. 37) y Braunstein (1983b, p. 171).

17. Entre los qom, ya en 1935 el misionero Arnott expresaba que uno de los motivos de las peleas entre los « clanes » era « que un hombre debidamente casado, esto es, un hombre cuya mujer ha tenido de él un hijo que está ya creciendo, la abandone por otra » (1935, p. 298).

18. Entre los wichí encontramos una idea semejante respecto de las consecuencias del incesto: tal como expresa Barúa, si dos parientes consanguíneos mantienen relaciones sexuales « toda la comunidad familiar [...] será completamente destruida » (2001, p. 43).

19. También Miller sostenía que « es difícil hacer una declaración consistente respecto de los patrones matrimoniales preferenciales » de los tobas (1966, p. 195).

20. Todas las traducciones de citas textuales fueron realizadas por mí (F. T.).

21. Específicamente, en su muestra de 50 matrimonios, Palmer registra once uniones consanguíneas: con tía (1), prima (4), sobrina (5) y nieta (1), todas en 1.er grado.

22. Un consejo-frase que los padres dicen a sus hijos para prevenir desgracias es « damaye arhuol'ec, arqaỹa, qarhuopi. Saishet da ỹaqa'a », cuya traducción sería "él [es] tu pariente, tu hermano, nuestros parientes. No [es/son] diferentes [afines potenciales] ».

23. Braunstein (1983a, p. 18) refiere a la existencia de la poliginia sororal tan sólo en aquellos grupos chaqueños (no precisa cuáles) en los que, en el pasado, la poliginia no era una práctica reprobada. 
24. Santo Domingo o Poxo-ỹaxaic Alhua es un antiguo asentamiento ubicado sobre la ribera norte del río Bermejo, a $15 \mathrm{~km}$ de Subteniente Perín, provincia de Formosa. Riacho de Oro o Dañal'ec Lacheugue se sitúa a $8 \mathrm{~km}$ de Subteniente Perín y se encuentra sobre los dos márgenes de la ruta nacional n. ${ }^{\circ}$ 95. San Carlos o Mala' Lapel está ubicado a $45 \mathrm{~km}$ de Comandante Fontana hacia el sur. Namqom representa uno de los asentamientos más poblados de Formosa, constituido hacia 1960 a $11 \mathrm{~km}$ de la capital de la provincia. Allí habitan familias provenientes de comunidades rurales tanto de la provincia de Formosa como de la de Chaco, aglutinadas en manzanas cuadriculadas, parcelas reducidas y lotes contiguos.

25. En realidad está apareciendo incluso una novena generación, ya que una mujer con ascendentes registrados en $\mathrm{G}+7$ ya tiene dos hijos.

26. La búsqueda hecha no diferencia entre medios hermanos y hermanos.

27. No se dan, sin embargo, matrimonios que pertenecerían a tres tipos de circuitos (por ej. « hermanas » que también serían « tías »y « sobrinas »).

28. Si nos quedamos aquí con una distancia generacional máxima de 2 es porque con búsquedas más amplias las cifras explotan de manera no manejable y poco útil. Por ej., con una distancia máxima de 3 (que abarca hasta casos donde dos primos en 2.o grado se casan con dos primos en 2.o grado) se dan 2213 circuitos de 1144 tipos, involucrando a 197 matrimonios y 321 cónyuges: los circuitos aumentan de un $567 \%$ para un incremento de matrimonios involucrados de tan sólo $18 \%$.

29. Entre los yanomami, las relaciones extramatrimoniales y la brujería son concebidas como la causa de los posibles sufrimientos de los parientes, y no causar tristeza en ellos es una de las máximas aspiraciones yanomami del buen vivir (Alès 2000). Las relaciones extramatrimoniales de las mujeres y la brujería son también entre los shuar y achuar las principales causas de conflictos entre comunidades locales (Mader y Gippelhauser 2000).

30. Entre los qom varios etnógrafos refirieron la actitud de los jóvenes respecto de la sexualidad antes del matrimonio. Según Karsten (1932, p. 53) y Métraux (1946, p. 324), los indígenas del Chaco se caracterizaban por una gran libertad sexual. Karsten señala que, en los últimos tiempos, esta libertad sexual se fue degenerando en prostitución que la moral del grupo no desaprueba (ibid., p. 57). Métraux (ibid.) y Cordeu y De los Ríos (1982, p. 159) dicen que entre las tribus del Bermejo y Pilcomayo las mujeres tomaban la iniciativa en las aventuras amorosas.

\section{REFERENCIAS CITADAS}

ALÈs Catherine

2000 "Anger as a marker of love: the ethic of conviviality among the Yanomami », in Joanna Overing y Alan Passes (eds.), The anthropology of love and anger. The aesthetics of conviviality in native Amazonia, Routledge, Londres, pp. 133-151.

ARNOTT John

1935 "Vida amorosa y conyugal de los indios del Chaco », Revista geográfica americana, 4 (26), pp. 293-303.

Azara Félix de

1817 Viaggi nell' America meridionale. Sonzogno y comp., Milano [1809].

BALMORI Clemente

1957 «Notas de un viaje a los tobas », Revista de la Universidad (La Plata), 2, pp. 23-36.

BARRY Laurent y Michael GASPERONI

2008 «L'oubli des origines. Amnésie et information généalogiques en histoire et en ethnologie », Annales de démographie historique, (116) 2, pp. 53-104. 
BARÚA Guadalupe

$2001 \quad$ Semillas de estrellas. Los nombres entre los wichí, Dunken, Buenos Aires.

2007 Un arte delicado. Relaciones entre el parentesco, el conflicto y el acontecimiento entre los wichí del Chaco central, Dunken, Buenos Aires.

Bossert Federico, Pablo Sendón y Diego Villar

2009 «Relevancia de las teorías clásicas del parentesco para el estudio de las sociedades amerindias (Andes centrales, Amazonía y Gran Chaco) », Actas del VI Congreso argentino de americanistas 2008, Sociedad Argentina de Americanistas, Buenos Aires, pp. 35-64.

BRaUnSTEIN José

1976 «Terminología de parentesco toba » [inédito].

1983a «Algunos rasgos de la organización social de los indígenas del Gran Chaco », Trabajos de etnología, 2, pp. 9-102.

1983b «La passion amoureuse chez les Mataco: Kyutisli », Journal de la Société des Américanistes, 69, pp. 169-176.

Braunstein José y Elmer Miller

1999 Peoples of the Gran Chaco, Bergin \& Garvey, Westport.

BUCKWALTER Alberto

2001 Vocabulario toba, Equipo Menonita, Formosa.

CARrasco Nélida

1986 «Un análisis del matrimonio toba de Ensanche (provincia de Formosa) », Suplemento antropológico, 21 (1), pp. 219-261.

CombÈs Isabelle

2006 «Introducción: cuando el nombre no hace al índio », in Isabelle Combès (ed.), Definiciones étnicas, organización social y estrategias politicas en el Chaco y la Chiquitanía, Instituto francés de estudios andinos, col. « Actes et mémoires » 11, Lima, pp. 19-23.

CORDEu Edgardo y Miguel DE LOS Ríos

1969-1970 «Aproximación al horizonte mítico de los tobas », Runa, 12 (1-2), pp. 67176.

1982 «Un enfoque estructural de las variaciones socioculturales de los cazadores-recolectores del Gran Chaco », Suplemento Antropológico, 17 (1), pp. 131-195.

De Los Ríos Miguel

1978-1979 «La expresión de la afección amorosa en la etnia mataco », Scripta ethnologica, 5, pp. 27-54.

Dell'ArCiPrete Ana

1991-1992 « Terminología de parentesco pilagá », Hacia una carta étnica del Gran Chaco, 4, pp. 9-19.

DucCI Fray Zacarías

1904 Los tobas de Tacaagalé, misión San Francisco Solano. Arte y vocabulario toba-castellano y un mapa, Imprenta La Buenos Aires, Buenos Aires. 
HÉRITIER Françoise

1981 L'exercice de la parenté, Le Seuil-Gallimard, París.

HAMBERGER Klaus e Isabelle DaILlant

2008 «L'analyse de réseaux de parenté: concepts et outils », Annales de démographie historique, 116 (2), pp. 13-52

Idoyaga Molina Anatilde

1976 «Matrimonio y pasión amorosa entre los mataco », Scripta ethnologica, 4 (1), pp. 46-67.

KARSTEN Rafael

1932 "Indian tribes of the Argentine and Bolivian Chaco. Ethnological Studies », Societas Scientiarum Fennica, 4 (1), pp. 10-236.

MADER Elke y Richard GiPPELHAUSER

2000 "Power and kinship in Shuar and Achuar society », in Peter Schweitzer (ed.), Dividens of kinship. Meanings and uses of social relatedness, Routledge, Londres/Nueva York, pp. 61-91.

Mendoza Marcela

1999 «The Western Toba: family life and subsistence of a former huntergatherer society », in Elmer Miller (ed.), Peoples of the Gran Chaco, Bergin \& Garvey, Westport, pp. 81-108.

Messineo Cristina

2003 Lengua toba (guaycurú). Aspectos gramaticales y discursivos, Lincom Europa Academic Publisher, col. « Lincom Studies in Native American Linguistics » 48, Múnich.

Messineo Cristina, Gustavo Scarpa y Florencia Tola

2010 Léxico, clasificación nominal y categorización etnobiológica en el Gran Chaco, Universidad de La Pampa, La Pampa.

MÉtraux Alfred

1937 «Études d'ethnographie toba-pilagá (Grand Chaco)», Anthropos, 32 (1-2), pp. 171-194; (3-4), pp. 378-401.

1946 «Ethnography of the Gran Chaco », in Julian H. Steward (ed.), Handbook of South American Indians, vol. 1, Smithsonian Institution, Washington, pp. 197-370.

MiLLER Elmer

1966 «Toba kin terms », Ethnology, 2 (5), pp. 194-201.

1979 Los tobas argentinos. Armonía y disonancia en una sociedad, Siglo XXI, México.

1980 A critically annotated bibliography of the Gran Chaco Toba, Human Relations Area Files, New Haven.

NoRDENSKIöLd Erland

1912 "La vie des Indiens dans le Chaco: Amérique du Sud», Revue de Géographie, 6 (3), pp. 1-278. 
Palavecino Enrique

1933 «Breve noticia sobre un viaje etnográfico al Chaco central», Revista geográfica americana, 23 (2), pp. 77-110.

PALMER John

2005 La buena voluntad wichí. Una espiritualidad indigena, APCD/ CECAZO/EPRAZOL, Grupo de Trabajo Ruta 81, Formosa (Salta).

RICHARD Nicolas

2011 "La querelle des noms. Chaînes et strates ethnonymiques dans le Chaco boréal », Journal de la Société des Américanistes, 97 (2), pp. 201-230.

SIFFREDI Alejandra

1973 «La autoconciencia de las relaciones sociales entre los yojwaja-chorote », Scripta ethnologica, 1, pp. 71-103.

SúSNIK Branislava

1978 Los aborígenes del Paraguay. I: Etnología del Chaco Boreal y su periferia (siglos XVI y XVII), Museo etnográfico Andrés Barbero, Asunción.

ToLA Florencia

2006 « Estrategias matrimoniales en el proceso de repliegue y apertura de las parentelas toba (qom) », Revista de antropología, 49 (2), pp. 667-687.

Tola Florencia y Carlos Salamanca

2009 «Una revisión de las terminologías de parentesco y del régimen de alianza matrimonial entre los toba (qom) del Chaco argentino ", Actas del VI Congreso argentino de americanistas 2008, Sociedad Argentina de Americanistas, Buenos Aires, pp. 379-393.

VeLLaRd Jehan Albert

1969 Vocabulario toba, chiriguano, chané, Facultad de Filosofía y Letras, Buenos Aires. 